\title{
Fluorescence Quenching of Norfloxacin by Divalent Transition Metal Cations
}

\author{
Hyoung-Ryun Park, Jung-Ja Seo, Sung Chul Shin, ${ }^{\dagger}$ Hycong Su Lee, ${ }^{\hat{*}}$ and Ki-Min Bark ${ }^{+, *}$
}

\author{
Department of Chemistry and Nano Technology Research Center, Chonnam National University. Gwangit 500-757, Korea \\ "Deparment of Chemistrv and Research Insilite of Life Science, Gyeongsang National Lniversity; Chinju 660-701. Korea \\ ${ }^{\ddagger}$ Department of Chemical Edacation and Research Institue of Life Science, Gyeongsang National University. \\ Chinin 660-701, Korea. "E-mail: kiminb'agnu.ac.kr \\ Received Jily l2, 2007
}

\begin{abstract}
Fluorescence quenching of norfloxacin (NOR) by $\mathrm{Cu}^{2-}, \mathrm{Ni}^{2-}, \mathrm{Co}^{2+}$ and $\mathrm{Mn}^{2-}$ was studied in water. The change in the fluorescence intensity and lifetime was measured as a function of quencher concentration at various temperatures. According to the Stern-Volmer plots, the NOR was quenched both by collisions and complex formation with the same quencher. However, the static quenching had a more important effect on the emission. Large static and dynamic quenching constants support significant ion-dipole and orbital-orbital interactions between NOR and cations. The both quenching constants by $\mathrm{Cu}^{2+}$ were the largest among quenchers. Also, quenching mechanism of $\mathrm{Cu}^{2+}$ was somewhat different. The change in the absorption spectra due to the quencher provided information on static quenching. The fluorescence of NOR was relatively insensitive to both the dynamic and static quenching compared with other quinolone antibiotics. This property can be explained by the twisted intramolecular charge transfer.
\end{abstract}

Key Words : Fluorescence quenching. Norfloxacin. Transition metal cation, Stern-Volmer plot. Intramolecular charge transfer

\section{Introduction}

The fluoroquinolone antibacterial agents, such as norlloxacin (NOR) are one of the most frequently prescribed groups of medicine because they can be used to treat a broad spectrum of bacterial infections. ${ }^{1-3}$ In 1980 . NOR was lirst synthesized by introducing a piperazinyl group at 7-carbon atom, as shown in Scheme 1. It was soon realized that NOR was much more active in vitro and it showed a broader range of antibacterial activity compared with the drugs without a piperazinyl group. ${ }^{4.5}$ The different types of fluoroquinolone antibiotics, with or without the piperazine substituent, exhibit quite different antibacterial responses and chemical properties in various environments. ${ }^{6-8}$ Therefore, it is very important to study the physical and chemical properties of these molecules because this investigation can provide essential knowledge in our understanding of the mechanism of antibacterial activity and cutaneous photosensitization of these antibiotics." using systems that mimic biological enviromments such as aerosol-OT (AOT) reverse micelle or $\mathrm{H}_{2} \mathrm{O}-\mathrm{CH}_{3} \mathrm{OH}$ and $\mathrm{H}_{2} \mathrm{O}-\mathrm{CH}_{3} \mathrm{CN}$ mixed solvents because it is difficult to do this<smiles></smiles>

Scheme 1 hind of work in vivo directly. ${ }^{8.12-14}$

I has been known that 1:1 complexes are formed between these molecules and some divalent cations by ion-dipole interaction using the 4-keto oxygen and the ionized 3carboxylic acid group. ${ }^{15}$ The ability of the quinolone antibiotics to interact with some cellular components is mediated by their complexation with divalent metal cations. ${ }^{\text {(1. } 1 \text { (1-18 }}$ Such interaction between these medicines and metal cations can cause the fluorescence quenching. Therefore, valuable physicochemical properties of these compounds can be obtained using fluorescence quenching study by metal cations. ${ }^{19}$

Fluorescence quenching refers to any process which decreases the fluorescence intensity of a given molecule. A variety of processes can caluse quenching of fluorophore. These include excited state reactions, energy transfer, complex formation, and collisional quenching. ${ }^{20}$ One such process is collisional or dynamic quenching, which involves the collision and subsequent formation of a transient complex between an excited state fluorophore and a ground state quencher. The excited state complex dissociates upon radiative and nonradiative deactivation, leaving both the fluorophore and quencher in the ground state. Dynamic quenching is diffusion controlled because the quencher must diffuse to the fluorophore during the lifetime of the excited state. Another important quenching mechanism is static quenching. whereby a nonfluorescent complex is formed between a ground state fluorophore and quencher. Static quenching is a frequent complicating factor in the analysis of dynamic quenching.

In this paper, the quenching of NOR tluorescence by $\mathrm{Cu}^{2-}$, $\mathrm{Ni}^{2-}, \mathrm{Co}^{2-}$ and $\mathrm{Mr}^{2-}$ was studied. All these metal quenchers 
belong to the first transition metal series. With the previous study for quinolone antibiotics such as ofloxacin (OFL) and flumequine (FLU), this work will provide further insight into the chemical properties and antibacterial activity of this drug. ${ }^{19}$

\section{Experimental Section}

Reagents and materials. NOR was purchased from Sigma Chemical Co. (St. l.ouis, MO) and used without further purification. The reagents used as metal quenchers, $\mathrm{CuCl}_{2} \cdot 2 \mathrm{H}_{2} \mathrm{O}, \mathrm{CoCl}_{2} \cdot 6 \mathrm{H}_{2} \mathrm{O}, \mathrm{NiCl}_{2} \cdot 6 \mathrm{H}_{2} \mathrm{O}$ and $\mathrm{MnCl}_{2} \cdot 4 \mathrm{H}_{2} \mathrm{O}$. were obtained from Aldrich Chemical Co. (Milwaukee, WI. $\mathrm{ACS}$ reagent grade) and used as received. These chemicals were dried for $48 \mathrm{hr}$ in a vacuum below $1 \times 10^{3}$ torr with $\mathrm{P}_{2} \mathrm{O}_{5}$ at room temperature and kept in the desiccator over $\mathrm{P}_{2} \mathrm{O}_{5}$. To prepare buffer solution $(\mathrm{pH}=7.5)$, tris(hydroxymethyl)aminomethane (tris), $\mathrm{KCl}$ and $\mathrm{HCl}$ were purchased from Aldrich Chemical $\mathrm{Co}$. and used as received. The aqueous solutions were prepared using doubly distilled and deionized water, which was obtained by passing doubly distilled water through a deionization system [Barnstead (U.S.A.) Nanopure [I]. The concentration of samples was lower than $3 \times 10^{5} \mathrm{M}$ in order to avoid any solute-solute interactions and self-absorption. The procedure for preparing samples and tris buffer, and eliminating the dissolved oxygen in the sample was explained elsewhere. ${ }^{12.1^{10}}$ The fircal concentration of tris buffer was $0.050 \mathrm{M}$ tris and $0.10 \mathrm{M}$ $\mathrm{KCl}$.

Instruments. UV/Vis absorption spectra were obtained using a Perkin-Elmer Lambda 900 spectrophotometer. The steady-state fluorescence emission spectra were obtained on a Perkin-Elmer LS-50B spectrofluorometer. To improve reproducibility, each sample was scanned 10 times and the average of these measurements was recorded as emission spectrum. The sample temperature was controlled using a Julabo MP-5A temperature circulator $\left( \pm 0.5{ }^{\circ} \mathrm{C}\right)$. The quantum yields ( $\Phi$ ) were measured using quinine sulfate ( $\Phi$ $=0.546)$ and anthracene $(\Phi=0.27)$ as a reference. ${ }^{21-2.3}$. The phase-modulation method was used to obtain fluorescence lifetimes by SLM48000S (SLM Aminco, Rochester, NY) spectrofluorometer. The procedure for lifetime measurements was described in previously published papers. ${ }^{8.20,24-26}$

\section{Results and Discussion}

Fluorescence quenching. As shown in Figure 1 , the absorption spectrum of NOR contains two bands, a strong peak at $\cdots 275 \mathrm{~nm}$ and a small peak at $\cdots 325 \mathrm{~nm}$ in water. The steady state fluorescence emission spectra in aqueous solution exhibited strong, broad structureless band with large Stokes' shift as shown in Figure 2. Because the shapes of the absorption and emission spectra are different, the molecular geometry in ground and excited states will significantly be different. The fluorescence properties of NOR were quite sensitive to the physicochemical properties of the environments. ${ }^{8.13}$

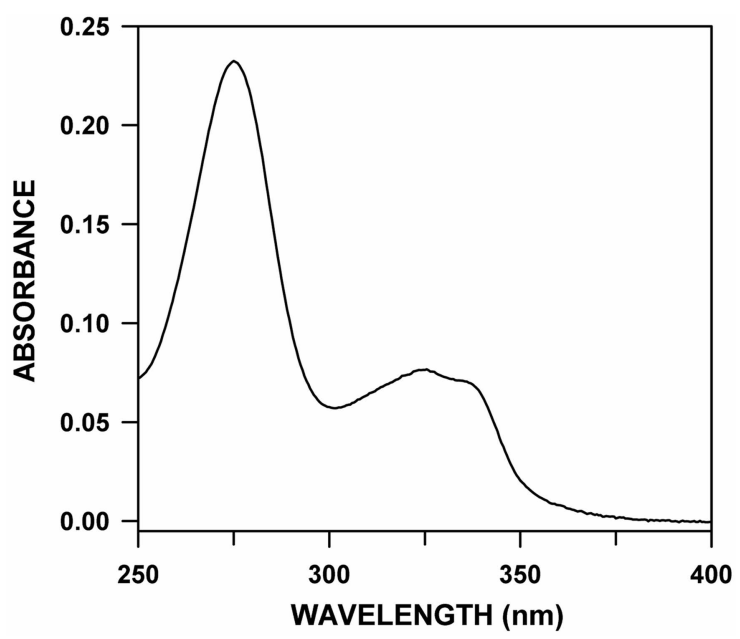

Figure 1. Absorption spectrum of $7 \times 10^{-6} \mathrm{M}$ \OR in water.

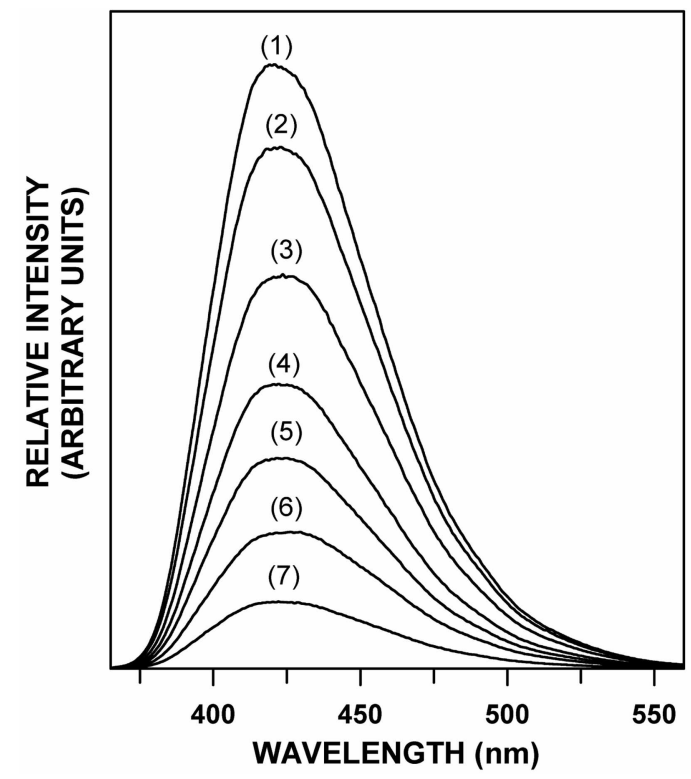

Figure 2. Fluorescence emission spectra of $7 \times 10^{\circ} \mathrm{M}$ NOR acpueous solution at $0^{\circ} \mathrm{C}$ in the presence of $\mathrm{Cu}^{2+}\left(\hat{\alpha}_{\mathrm{k} x} \quad 325 \mathrm{~nm}\right)$. Concentration of $\left(\mathrm{u}^{2-}(\mathrm{M})\right.$ : (1) 0.0 : (2) $1.2 \times 10^{-6}$ : (3) $2.4 \times 10^{-6}$ : (4) $3.6 \times 10^{-6}:(5) 4.8 \times 10^{-6}:(6) 6.0 \times 10^{-6}:(7) 8.4 \times 10^{-6}$.

When metal quenchers, $\mathrm{Cu}^{2-}, \mathrm{Ni}^{2+}, \mathrm{Co}^{2+}$ and $\mathrm{Mn}^{2+}$, were added to a NOR solution, very sensitive fluorescence quenching occurred even at very low concentrations as shown in figure 2. However, the shape and position of the emission spectra remained the same until the intensity fell below the detection limit. Figure 3 and 4 show the SternVolmer plot and lable 1 exhibits fluorescence quenching constants by these metal quenchers at various temperatures. respectively. In these plots and lable. following characteristic features can be observed.

First, the static $\left(\mathrm{K}_{\mathrm{s}}\right)$, dynamic Stern-Volmer $\left(\mathrm{K}_{\mathrm{L}}\right)$, and bimolecular $\left(k_{1}\right)$ quenching constants are quite large as presented in lable 1. The definition of $\mathrm{k}_{\mathrm{t}}$ is as follow: $\mathrm{K}_{\mathrm{L}}=$ $\mathrm{k}_{\mathrm{l}} \tau_{0}$, where $\tau_{0}$ is the fluorescence lifetimes in the absence of a quencher. The $\mathrm{k}_{\mathrm{q}}$ values, particularly for $\mathrm{Cu}^{2+}$, are much larger than those possible for a diffusion-controlled quen- 

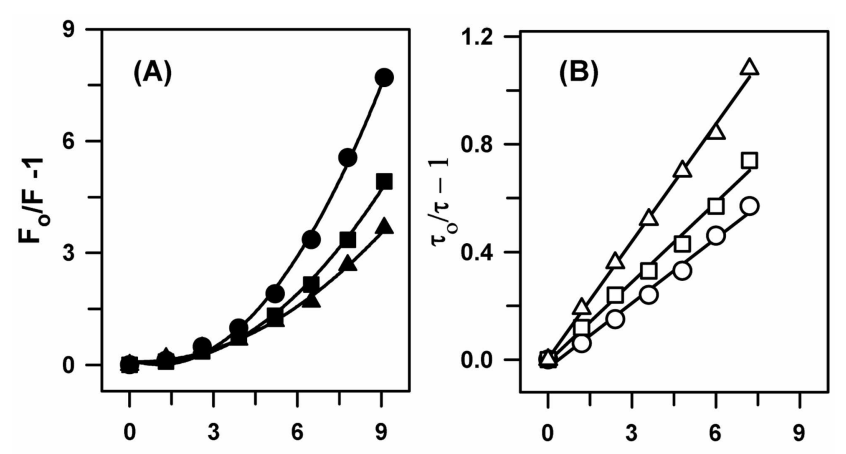

$\left[\mathrm{Cu}^{2+}\right] \times 10^{-6} \mathrm{M}$
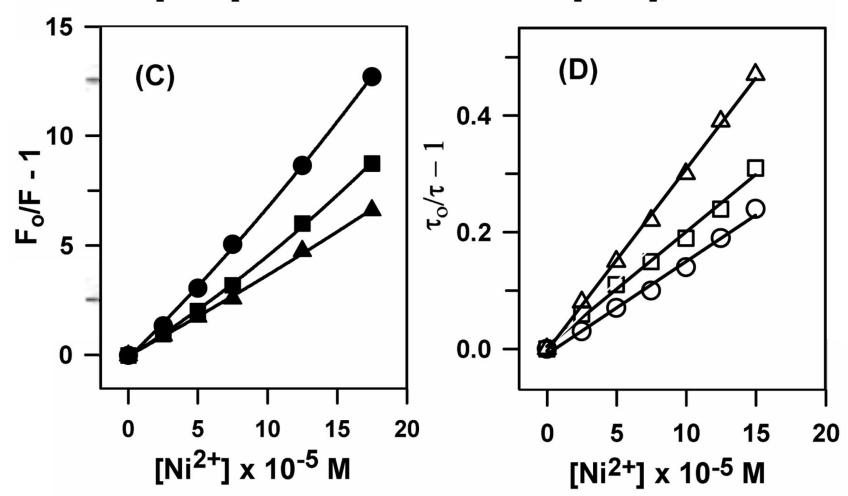

Figure 3. Stern-Volmer plots for the quenching of $Y O R$ lluorescence by $\mathrm{Cu}^{2-}$ and $\mathrm{Ni}^{2}$ at various temperalures: $(A) \mathrm{Cu}^{2+}$ : $10^{\circ} \mathrm{C}(\mathrm{C}) .30^{\circ} \mathrm{C}(\mathrm{C})$. and $60^{\circ} \mathrm{C}(\mathrm{A})$. (B) $\mathrm{Cu}^{-2}: 10^{\circ} \mathrm{C}(\mathrm{C}), 30^{\circ} \mathrm{C}$ (1 ). and $60^{\circ} \mathrm{C}(\mathrm{A}),(\mathrm{C}) \mathrm{Ni}^{2}: 10^{\circ} \mathrm{C}(\mathrm{O}) .30^{\circ} \mathrm{C}(\mathbf{\square})$, and $60^{\circ} \mathrm{C}$ (4). (D) $\times \mathrm{in}^{2}: 10^{\circ} \mathrm{C}(\mathrm{C}) .30^{\circ} \mathrm{C}\left(\right.$ ) and $60^{\circ} \mathrm{C}(\mathrm{A})$.

ching in solution. Similar large quenching constants were also reported for the other quinolone antibiotics such as OFL and FLU. ${ }^{19}$ Usually large $k_{\text {iq }}$ beyond the diffusion-controlled limit indicates that some types of binding interaction exist between fluorophore and quencher. ${ }^{2\left(0.27-z^{4}\right)}$ Therefore, this observation suggests that there are relatively strong iondipole and orbital-orbital interaction between NOR and metal quenchers. The complex formation between these medicines such as NOR, OFL and FLU, and divalent metal cations was reported previously. ${ }^{15}$ The magnitude of quenching constants is consistent with the formation constants between the medicine and metal quenchers.

In the spectrum (7) of Figure 2, the concentration of $\mathrm{NOR}$ and $\mathrm{Cu}^{2+}$ was similar to each other. Therefore, most of the NOR emission was quenched when the concentration ratio of fluorophore and quencher was close to $\mathrm{l}: \mathrm{l}$. As the $\mathrm{Cu}^{2+}$ concentration was larger than $8.4 \times 10^{-6} \mathrm{M}$, fluorescence
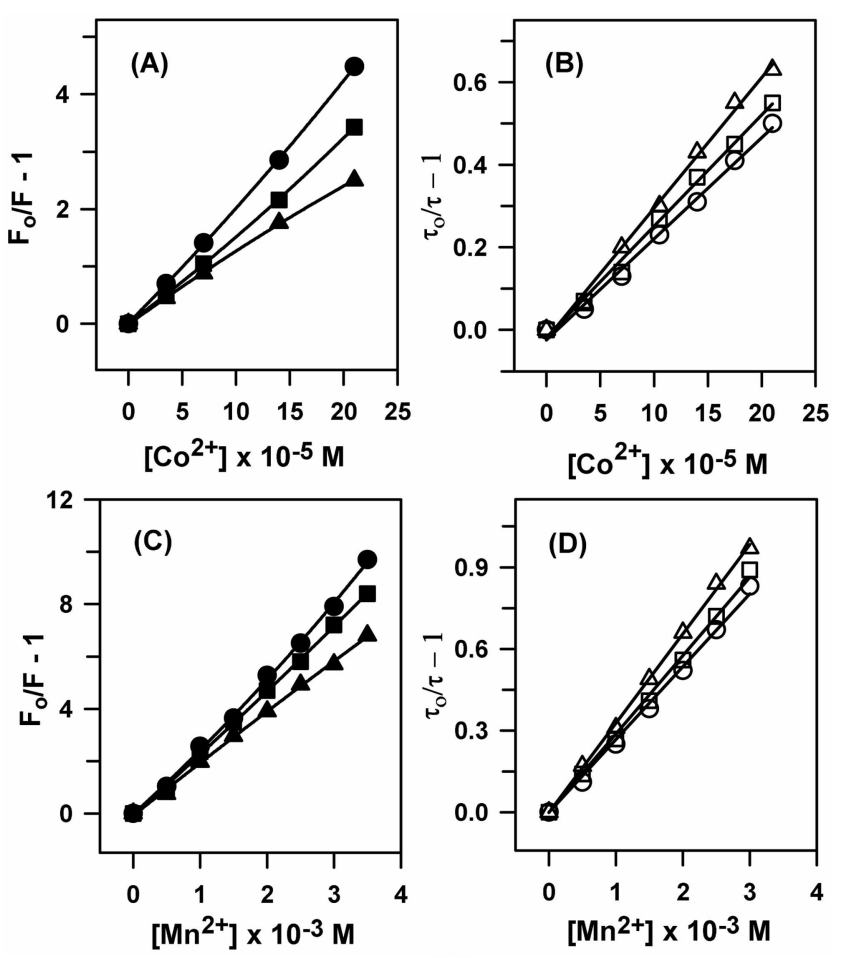

Figure 4. Stem-Volmer plots for the quenching of NOR fluorescence by $\mathrm{Co}^{2}$ and $\mathrm{Mn}^{21}$ at various temperatures: (A) $\mathrm{Co}^{21}$ : $10^{\circ} \mathrm{C}(\mathrm{C}) .30^{\circ} \mathrm{C}(\mathrm{\square})$, and $60^{\circ} \mathrm{C}(\mathrm{A}),(\mathrm{B}) \mathrm{Co}^{2}: 10^{\circ} \mathrm{C}(\mathrm{C}) .30^{\circ} \mathrm{C}$ $(\square)$, and $60^{\circ} \mathrm{C}(\hat{\mathrm{O}}) .(\mathrm{C}) \mathrm{Mn}^{2}{ }^{\circ}: 10^{\circ} \mathrm{C}(\mathrm{O}) .30^{\circ} \mathrm{C}(\boldsymbol{C})$, and $60^{\circ} \mathrm{C}$ (4). (D) $\mathrm{Mn}^{2-}: 10^{\circ} \mathrm{C}(\odot), 30^{\circ} \mathrm{C}(\sqsubset)$, and $60^{\circ} \mathrm{C}(\mathrm{A})$.

emission was not measured signiticantly. So, it can be assumed that almost all of the $\mathrm{Cu}^{2+}$ will form $1: 1$ complex with NOR or the distance between nearly all metal cation and molecule will be shorter than the radius of "sphere of action" within which the probability of quenching is unity. Once the fluorophore and quencher are this close, there exists a very high probability that quenching will occur before these molecules diffuse apart. As the quencher concentration increases, the probability increases that a quencher is within the first solvent shell of the fluorophore at the moment of excitation. ${ }^{20}$

Second, the change in the fluorescence intensity as a function of quencher concentration, $[(\mathrm{F} / \mathrm{t})-1]$ vs $[\mathrm{Q}]$, increases more rapidly as the temperature of sample decreases, where $\mathrm{F}$ and $\mathrm{F}_{0}$ are the fluorescence intensities in the presence and absence of the quencher, respectively, $Q$ is the fluorescence quencher. This suggests that static quenching has a great influence on the overall quenching process.

Table 1. Static Quenching Constants, $\mathrm{K}_{S}\left(\mathrm{M}^{-1}\right)$; Dy namic Stern-Volmer Quenching Constants, $\mathrm{K}_{D}\left(\mathrm{M}^{-1}\right)$; and I3imolecular Quenching Comstants, $k_{q}\left(\mathrm{M}^{-1} \mathrm{~ns}^{-1}\right)$, for $\mathrm{NOR}$ with various Divalent Cations. The uncertainty is $\leq 7 \%$

\begin{tabular}{|c|c|c|c|c|c|c|c|c|c|}
\hline \multirow[b]{2}{*}{ Cations: } & \multicolumn{3}{|c|}{$10^{\circ} \mathrm{C}$} & \multicolumn{3}{|c|}{$30^{\circ} \mathrm{C}$} & \multicolumn{3}{|c|}{$60^{\circ} \mathrm{C}$} \\
\hline & $\mathrm{K}_{\mathrm{s}}$ & $\mathrm{K}_{\mathrm{D}}$ & $k_{\text {u }}$ & $\mathrm{K}_{\mathrm{s}}$ & $\mathrm{K}_{\mathrm{D}}$ & $k_{\text {q }}$ & $K_{s}$ & $\mathrm{~K}_{\mathrm{D}}$ & $k_{4}$ \\
\hline $\mathrm{Cu}^{21}$ & $1.59 \times 10^{6}$ & $7.44 \times 10^{4}$ & $3.94 \times 10^{+}$ & $6.71 \times 10^{5}$ & $9.71 \times 10^{-4}$ & $5.03 \times 10^{4}$ & $3.05 \times 10^{5}$ & $1.46 \times 10^{5}$ & $9.93 \times 10^{+}$ \\
\hline $\mathrm{Ni}^{2} \cdot$ & $7.58 \times 10^{4}$ & 1500 & 700 & $3.82 \times 10^{4}$ & 2050 & 980 & 5840 & 3080 & 1830 \\
\hline $\mathrm{Co}^{21}$ & 3180 & 2290 & 1070 & 3090 & 2570 & 1280 & 2960 & 3020 & 1990 \\
\hline $\mathrm{Mn}^{21}$ & 510 & 270 & 120 & 150 & 290 & 170 & - & 330 & 210 \\
\hline
\end{tabular}


High temperature is likely to reduce the stability of the complexes, resulting lower static quenching constants. Third, the $\left[\left(\mathrm{F}_{\mathcal{O}} / \mathrm{F}\right)-1\right]$ is $\left[\mathrm{Cu}^{2+}\right]$ plots have a concave curvature towards the $\mathrm{y}$-axis. Also, this curvature increases as the temperature decreases. For $\mathrm{Ni}^{2+}, \mathrm{Co}^{2+}$ and $\mathrm{Mn}^{2+}$, these plots at $60^{\circ} \mathrm{C}$ are nearly a straight lines but the small concave curvature appears as the temperature decreases. However, the curvature of $\mathrm{Ni}^{2+}$ plot is somewhat larger than that of $\mathrm{Co}^{2-}$ and $\mathrm{Mr}^{2-}$. If the fluorophore is quenched both by collisions and by complex formation with the same quencher. the modified Stern-Volmer equation is second order with respect to $[\mathrm{Q}] .^{20}$ Therefore, this upward curvature suggests that both static and dynamic quenching occur by the same quencher. Fourth, the slope of $\left[\left(\tau_{v} / \tau\right)-1\right] \mathrm{ws}[\mathrm{Q}]$ plots increases as the temperature increases, where $\tau$ and $\tau_{\mathrm{s}}$ are the fluorescence lifetimes in the presence and absence of a quencher, respectively. In addition, these plots are linear straight lines. This change in lifetime by the quencher as a function of temperatures exhibits the dynamic portion of the observed quenching. ${ }^{20.30 .31}$ Because dynamic quenching depends upon diffusion. the bimolecular quenching constants, $k_{q}$, will be proportional to $T / \eta$, where $T$ is temperature and $\eta$ is solvent viscosity. Since viscosity is expected to decrease with increasing temperature, $k_{4}$ will increase with the increasing temperature. On the other hand, the only observed fluorescence is from the uncomplexed fluorophores in static quenching. Because the uncomplexed fraction is unperturbed, the lifetime remains $\tau_{v 0}$. Therefore, $\tau_{v}=\tau$ in static quenching but $\tau_{v} / \tau=\Gamma_{v} / \Gamma$ in dynamic quenching.

All of the static and dynamic quenching constants by $\mathrm{Cu}^{2+}$ are larger than those by other metal quenchers as shown in lable $]$. Also, the curvature of $\left[\left(\mathrm{Fo}_{\mathrm{v}} / \mathrm{\Gamma}\right)-1\right] v\left[\mathrm{Cu}^{2-}\right]$ plot is largest and increases most rapidly with decreasing temperature among all of the metal quenchers as shown in Figure 3 and 4 . In the dynamic portion of the observed quenching, the temperature dependence of the $\left[\left(\tau_{v} / \tau\right)-1\right] v s[\mathrm{Q}]$ plot is large in $\mathrm{Cu}^{2+}$ and $\mathrm{Ni}^{2-}$, but sinall in $\mathrm{Co}^{2+}$ and $\mathrm{Mn}^{2-}$, respectively. The $\mathrm{k}_{\mathrm{q}}$ for $\mathrm{Ni}^{2-}, \mathrm{Co}^{2+}$, and $\mathrm{Mn}^{2-}$ are very sinall compared with these for $\mathrm{Cu}^{2+}$. Particularly, the $\mathrm{K}_{\mathrm{q}}$ for $\mathrm{Ni}^{2-}$ is smaller than these for $\mathrm{Co}^{2-}$. The $\mathrm{K}_{\mathrm{s}}$ for $\mathrm{Ni}^{2-}$ is smaller than $\mathrm{Cu}^{2-}$ but larger than $\mathrm{Co}^{2+}$ and $\mathrm{Mn}^{2+}$. The relatively large $\mathrm{Ks}$ by $\mathrm{Ni}^{2+}$ quenching can be explained partially by the smaller ionic radius and larger nuclear charge of $\mathrm{Ni}^{2+}$ compared with $\mathrm{Co}^{2-}$ and $\mathrm{Mn}^{2+}$. These $\mathrm{K} s$ of $\mathrm{Ni}^{2+}$ decrease greatly as the temperature increases. When $\mathrm{Co}^{2+}$ is used as a quencher, the $\mathrm{Ks}$ is much smaller than those of $\mathrm{Cu}^{2+}$ and $\mathrm{Ni}^{2+}$ and the change of $\mathrm{Ks}$ as a function of temperature is also small. In $\mathrm{Mn}^{2-}$, the $\mathrm{K}_{\mathrm{s}}$ and $\mathrm{k}_{\mathrm{q}}$ are quite small. The $\mathrm{K}_{\mathrm{s}}$ for $\mathrm{Mn}^{2-}$ at 60 ${ }^{\circ} \mathrm{C}$ is too small to obtain with certainty. As expected, the $\mathrm{k}_{\mathrm{q}}$ by $\mathrm{Mn}^{2+}$ approach to the diffusion-controlled rate. It is clear that there is very weak orbital-orbital interaction between $\mathrm{Mn}^{2-}$ and NOR because the $3 d$ orbital of $\mathrm{Mn}^{2+}$ is half filled. The ion-dipole interaction between $\mathrm{Mn}^{2-}$ and NOR will also be weak because of the relatively large ionic radius and small nuclear charge.

$\mathrm{Cu}^{2-}$ is well known as an excellent quencher because it is a good electron scavenger on account of its electronic structure $\left(d^{i}\right)$. Also, because $\mathrm{Cu}^{2-}$ have large nuclear charge and the relatively sinall ionic radius compared with other metals. the ion-dipole interaction between $\mathrm{Cu}^{2+}$ and NOR will be strong. Furthermore. $\mathrm{Cu}^{2-}$ usually introduces easily accessible low energy levels, which is capable of quenching the fluorescent excited states of the molecules. ${ }^{32-3 \cdot 1}$

Complex formation between NOR and metal quenchers. The change in the absorption spectra due to the addition of metal can provide useful information on static quenching because the absorption spectra of the fluorophores will frequently be changed by the formation of the ground state complex. Therefore, the changes of NOR absorption spectra by metal cations were examined in a $\mathrm{pH}$ 7.5 buffer solution. In this physiological $\mathrm{pH}$, NOR will exist mainly as zwitterions. ${ }^{15}$ In the tris buffer solution, there was no evidence of the formation of a precipitate as $\mathrm{Cu}(\mathrm{OH})_{2}$ until the $\mathrm{Cu}^{2-}$ concentration reached $1 \times 10^{3} \mathrm{M}$. The complexes between NOR and cations will mainly be formed by the ion-dipole interaction suggested previously because no strong absorption bands due to orbital-orbital interactions between metal $d$ orbital and ligand are observed as shown in Figure $5 .^{15}$ When $\mathrm{Cu}^{2-}$ was added to the NOR aqueous
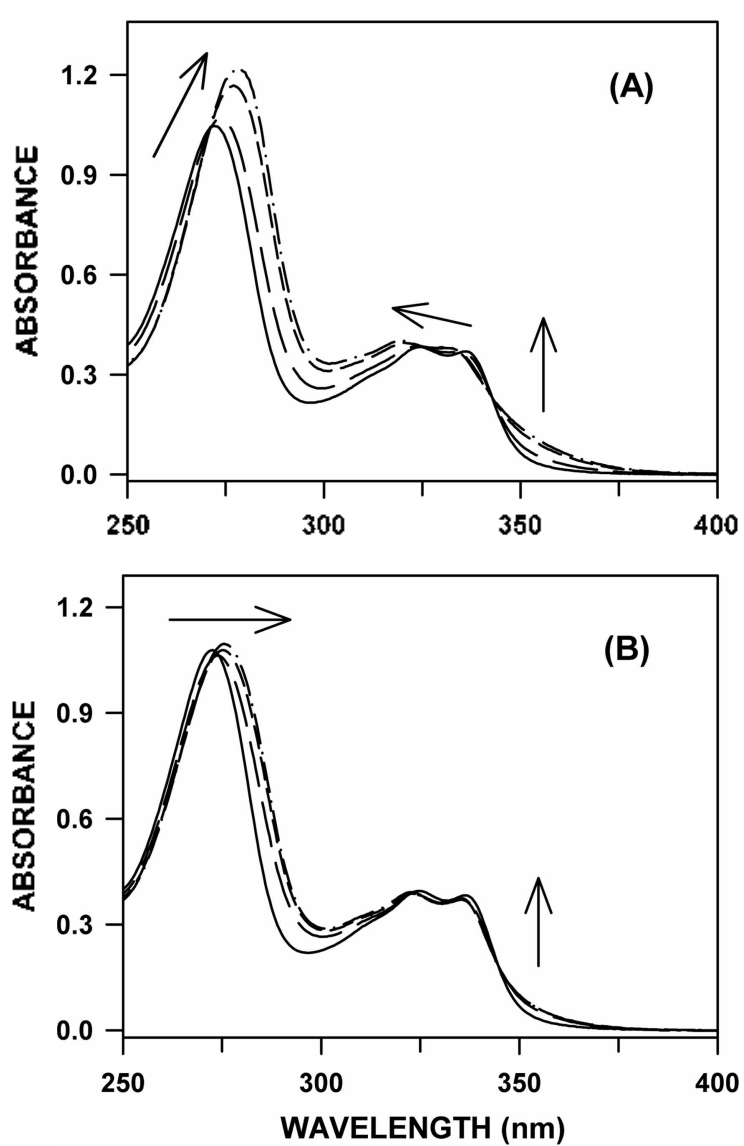

rigure 5. Change in the absorption spectra of $3 \times 10^{-5} \mathrm{M} \mathrm{NOR}$ aqueous solution by the addition of $\mathrm{C}^{2} \mathrm{u}^{21},(\mathrm{~N})$, and $\mathrm{CO}^{2-},(\mathrm{B})$. The concentration of $\mathrm{C}^{2}{ }^{2}$ and $\mathrm{Co}^{21}$ are as follows: $(-) 0.0 \mathrm{M} .(--)$ $1.0 \times 10^{-1} \mathrm{M},(\cdots) 5.0 \times 10^{-1} \mathrm{M} .\left(-{ }_{-1-}\right) 1 \times 10^{-3}$ M. Arrows indicate the change of spectra with the increase of metal concentrations. 
solution, the strong absorption band around $275 \mathrm{~nm}$ moved to a longer wavelength $(\sim 8 \mathrm{~nm})$ with a gradual increase in absorbance. The weak absorption band around $325 \mathrm{~nm}$ shifted to a shorter wavelength $(-6 \mathrm{~nm})$ with a small increase in absorbance. In addition, a sinall absorption band grew around $360 \mathrm{~nm}$. Isosbestic point was observed at $344 \mathrm{~nm}$. In this case, there will relatively be strong orbital-orbital interactions in addition to the ion-dipole interaction between NOR and $\mathrm{Cu}^{2-}$ because the change in the absorption bands and the appearance of a new band are relatively large. These complexes will involve both the 4-keto oxygen and the ionized 3-carboxylic acid groups because these ketone and carboxyl group correspond to a different chromophore and both these two absorption bands change as a result of the complex formation. ${ }^{\left(5.1^{4}\right)}$ This relatively strong orbital-orbital interaction can explain the large static quenching constant between $\mathrm{NOR}$ and $\mathrm{Cu}^{2-}$.

According to the crystal structure of the ciprofloxacin (CIP) $-\mathrm{Cu}^{2-}$ complex reported recently, metal cations are usually bonded to the oxygen atoms of the carbonyl and carboxylic groups of the CIP and exhibit an octahedral, or square pyramidal geometry. ${ }^{35}$ Because CIP and NOR belong to the same class of quinolone antibiotics having similar molecular structure. $\mathrm{NOR}$ and $\mathrm{Cu}^{2-}$ will form complex having the same structure roughly with the $\mathrm{CIP}_{-}-\mathrm{Cu}^{2+}$. When $\mathrm{Ni}^{2+}, \mathrm{Co}^{2-}$, and $\mathrm{Mn}^{2+}$ were added, the change in the spectra exhibited approximately the same pattern but the spectral change was small compared with the case of $\mathrm{Cu}^{2+}$. The extent of the spectral change due to the addition of quenchers is consistent with the size of $K_{s}$ by metal cations.

Specific fluorescence properties of $\mathrm{NOR}$. Because $\mathrm{NOR}$ has an electron donor, the piperazinyl group, and an electron acceptor, the keto oxygen, NOR is regarded as a good twisted intramolecular charge transfer (TICl) molecule in the excited state. ${ }^{13}$ Since the intramolecular charge transfer (ICI) in the $S_{1}$ state is accelerated by water, NOR is present in aqueous solutions mainly in the charge transferred zwitterionic form, $\mathrm{S}_{1}(\mathrm{CT})$, as shown in Scheme 2. However, NOR is present in the molecular form, $\mathrm{S}_{1}(\mathrm{M})$, in organic solvent such as $\mathrm{CH}$ lone pair electrons of the I-nitrogen atom of the piperazinyl group attached directly to 7-carbon will participate to some extent the delocalization of the $\pi$ electrons in the quinoline nucleus of the NOR. Owing to these reasons, NOR exhibited specific fluorescence properties in various systems such as $\mathrm{AO}^{\prime}$ micelle or aqueous-organic solvent inixtures. ${ }^{8.13}$

To investigate the fluorescence properties of NOR, the quenching constants of NOR was compared with those of other quinolone antibiotics such as FLU. ${ }^{19} \mathrm{FI}, \mathrm{U}$ don't have piperazinyl group, electron donor. Therefore, any specific chemical properties such as excited state IC $T$ is not observed

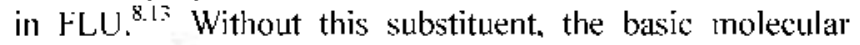
structure of NOR and FLU is similar. When the strongest quencher, $\mathrm{Cu}^{2+}$, was used, the $\mathrm{K}_{\mathrm{s}}$ and $\mathrm{k}_{q}$ of NOR were similar to those of FLU. ${ }^{(1)}$ For other metal guenchers, particularly for $\mathrm{Ni}^{2+}$, both the static and dynamic quenching constants of FLU were much larger than those of NOR. For $\mathrm{Ni}^{2-}, \mathrm{Co}^{2+}$ and $\mathrm{Mn}^{2+}$ quenchers, the difference in the $\mathrm{K}_{\mathrm{s}}$ values between NOR and Fl. U was quite large compared with the difference in the formation constants $\left(\mathrm{K}_{r}\right) .^{{ }^{\left(5.1^{14}\right)}}$

Although most of the NOR is present in $\mathrm{S}_{1}(\mathrm{CT})$ form in aqueous solution, some of $S_{1}(7)$ and $S_{1}(P 7)$ species also exists due to the resonance. So. NOR has several resonance forms in the excited state but FUL doesn't exhibit this kind

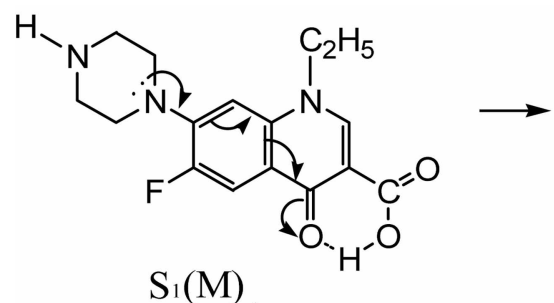

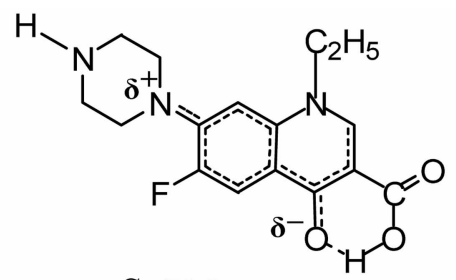

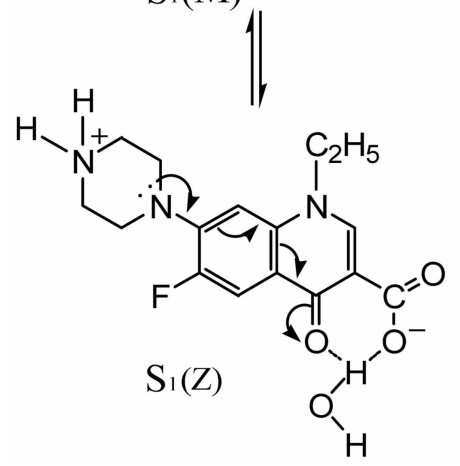

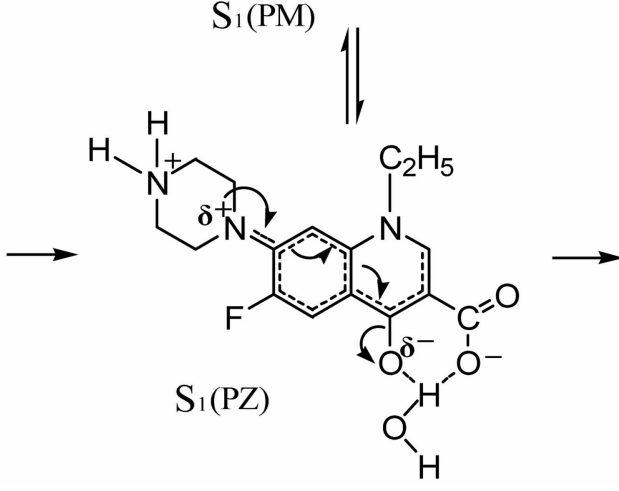

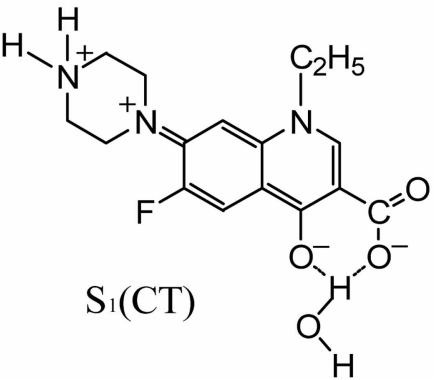

Increasing solvent polarity 
of property. Usually. the additional resonance forms lead to a stronger fluorescence emission. Furthennore. in aqueous solution. the difference of geometry and dipole moment between $S_{\circ}$ and $S_{\text {] }}$ state of NOR is very large compared with that of FLU, ${ }^{8,13}$ If the geometry change between different electronic states increases, the internal conversion rate usually decreases. Therefore, the NOR in water has a very high quantum yield and a short lifetime compared with that in organic solvents. Owing to these reasons, the NOR is relatively insensitive to fluorescence quenching by metal cations. particularly static quenching. compared with FLU although NOR has large quenching constants in this case. All these observations are one of the characteristic chemical properties of the NOR molecule.

\section{Conclusions}

When the metal cations such as $\mathrm{Cu}^{2+}, \mathrm{Ni}^{\hat{2}^{+}} \cdot \mathrm{Co}^{2+}$ and $\mathrm{Mn}^{2+}$ were added as quenchers, the fluorescence emission of NOR was quenched very efficiently by both collisions and complex formation with the same quencher. This large $\mathrm{K}_{\mathrm{s}}$ and $k_{\mathrm{f}}$ supports the existence of relatively strong ion-dipole and orbital-orbital interaction between NOR and metal quenchers. Furthermore. static quenching has more important effect on the fluorescence properties of NOR. $\mathrm{Cu}^{2-}$ is the strongest quencher among all of the metal cations examined. This might be because $\mathrm{Cu}^{\hat{2}^{-}}$is an excellent electron scavenger and introduces easily accessible low energy levels. In both static and dynanic quenching, the quenching mechanisn by $\mathrm{Cu}^{2-}$ is somewhat different from the mechanism by $\mathrm{Ni}^{2+}, \mathrm{Co}^{2+}$. and $\mathrm{Mn}^{2+}$. For all the metal cations, both carboxylic and carbonyl oxygen atoms will be involved in the chemical interaction between metals and ligand.

Because NOR is a TICT molecule in water, this molecule has additional resonance forms in the $\mathrm{S}_{\text {] }}$ state, and geonetry and dipole moment change are large during electronic transition. Therefore, NOR has shown many characteristic fluorescence properties in various biological mimic sýstems. In this study it was found that NOR was relatively insensitive to both the dynamic and static quenching compared with other quinolone antibiotics although the spectroscopic properties of NOR were very sensitive to the environments. In addition. this property was significant when relatively weak quenchers $\mathrm{Ni}^{2+} \cdot \mathrm{Co}^{2-}$, and $\mathrm{Mu}^{2-}$ were used. not $\mathrm{Cu}^{2+}$. This result is another peculiar fluorescence property that provides further evidence that excited state NOR exhibits TICT in aqueous solution. These chemical properties of NOR may be related to the significant improvement in the antibacterial activity due to the introduction of a piperazinyl group at the 7-carbon atom.

\section{References}

1. Appelbaum. P. C.: Hunter. P. A. Int. J. Anthicrob. Agent 2000.
16.5.

2. Mizuki. Y.: Fujiwara. I.: Yamaguchi. I. J. Antimichob. Chemother. 1996. 37(Sipp) Al. 41 .

3. Ball. P. J. Antimicrob. Chemother 2000. 46(Topic T1). 17.

4. Koga. H.: Itoh, A.; Murayama. S.: Suzue. S.; Irikura. T. J. 1 led. Chem $1980,23,1358$.

5. Satz-Nebot. V.: Valls. I.: Barbero D: Barbosa. T. Acta Chemica Scamdinavica 1997.5].896.

6. Andriole. V. I.: Stnith. J. T.: Lewin. C. S. The Ounolones: Academic press: New York, U.S.A., 1988: p 23.

7. Martinez, L: Bilski. P: Chignell. C. F. Photochem. Photobiol. 1996. $6 t_{3}, 911$

8. Park. H. R.: Lee. H. C.: Kim. T. H.: Lee. T. K.: Yang. K.: Bark. K. M. Photchem. Photobiol. 2000. 7l.281

9. Kan1g. J. S.: Kiml. T. H.: Park. K. B.: Chung. B. H.: Youn1. J. I. Photodematol Photommmol. Photomed 1993. 9. 159.

10. Sun. Y. W: Heo. E. P: Cho. Y. H.: Bark, K. M.: Yoon, T. J.: Kim. T. H. Photodematol Photoinmunol. Photomed 2001, 17. 172 .

11. Ferguson. J. Photochem. Photobiol. 1995.62.954.

12. Park. H. R.: Oh. C. H.: Lee. H. C.: Lim. S. R.: Yang. K.: Bark. K M. Photochem. Photobiol, 2004, 80,554 .

13. Park, H. R.: Oh. C. H: Lee, H. C.: Lee J. K.: Yang. K.; Bark, K M. Photochem. Photobiol, 2002, 75, 237 .

14. Rettig. W. J. Mol Structure 1982.84.303

15. Park. H. R.: Chung. K. Y.: Lee. H. C.: Lee. T. K.: Bark. K. M. Buth Korem Chem. Soc. 2000. 21. 849.

16. Slater. J.: Mildvan, A.; Loeb, L. Biochem. Biophys. Res. Conmun 1971. H, 37.

17. Springgate, C.: Mildvan. A.; Abramson, R.: Engle. J.; Loeb. L. d. Biol. Chem. 1973. 2+8. 5987.

18. Valetzuela. P: Morris. R.: Faras. A.: Levinson. W.: Rutter. W Biochent Biophns. Res Commum. 1973.53. 1036.

19. Park, H. R.: Oh. C. H.: Lee. H. C.: Choi. J. G.: Jung, B. I.: Bark, K M. Bull. Kowan Chem. Soc. 2006, 27.2002.

20. Lakowicz, J. R. Principles of flonscence spectroscopv 2nd ed. Kluwer Acadenic Plet1um Publishers: New York. U.S.A.. 1999

21. Eaton. D. F. Reference conponds for fluorescence meastiknent. IUPAC Orgaric Chem. Divisionl: Wilmington. U.S.A.. 1987 . p 1.

22. Bark. K. M.: Foree. R. K. Spectrochin. Acta 1993, 49(A). 1605.

23. Demas. J. N.: Grosby, G. A. J. Ph's. Chem. 1971. 75. 2463.

24. Zhang. T.: Bright. F. V. J. Phws Chent 1991. 95.7900.

25. Lakowicz. T. R.: Lackzo. G: Gryczynski. I.: Szmacinski. H.: Wiczk. W. J. Photochem. Photobiol B Biol. 1988. 2.295.

26. Jameson. D. M.: Gratton. E.: Hall. R. D. Appl. Spectrosc. Rev. 1984. 20,105

27. Kessler. M. A Anal Chim Acta 1998. 36t, 125.

28. Gonzalez-Jimmenez. I.: Frutos. G.: Cayre. I. Bichent. Pham acol. 1992. H. 824

29. Thulbom. K. R.: Sawyer. W. H. Biochin. Biophtws Acta 1978. $511,125$.

30. Seidel, C. A. M: Schulz, A.; Sauer. M. H. M. J. Phys. Chem. 1996. 100,5541 .

31. Kubota. Y.: Motoda. Y.: Shigemune. Y.: Fujisaki. Y. Photochent. Photobiol. 1979. 29. 1099.

32. Posolhov. Y.: Kus. M.: Biner. H.: Gumus. M. K.: Tugeu. F. T.: Aydemir, E.: Kaban, S.: Icli, S. J. Photochem. Photobiol 2004. 161. 247.

33. Fabbrizzi, L: Licchelli. M.: Pallavicini. P. Acc. Chem. Res. 1999. 32. 846.

34. Fabbrizzi. L.: Poggi. A. Chem. Soc. Rev 1995. 24. 197.

35. Drevensek. P.: Turel. I.: Uתrih. N. P. J. Inorg. Biochem. 2003. 96. 407 . 